\title{
The kallikrein-kinin system, but not vascular endothelial growth factor, plays a role in the increased vascular permeability associated with ovarian hyperstimulation syndrome
}

\section{H Kobayashi, Y Okada, T Asahina, J Gotoh and T Terao}

Department of Obstetrics and Gynecology, Hamamatsu University School of Medicine, Handacho 3600, Hamamatsu, Shizuoka, 431-31, Japan

(Requests for offprints should be addressed to H Kobayashi)

\begin{abstract}
Ovarian hyperstimulation syndrome (OHSS) is a severe complication arising from controlled stimulation treatment. Vascular endothelial growth factor (VEGF) has recently emerged as an important factor which may be responsible for the hyperpermeability seen in OHSS. The purpose of the present study was to investigate and compare the mechanisms by which ascites in patients with OHSS and ovarian carcinoma induce increases in vascular permeability in an in vitro assay and an in vivo animal experiment. We found 8 -fold lower VEGF levels in ascites from patients with OHSS than in those from patients with ovarian carcinoma. Although VEGF is produced by the ovaries, it is not necessarily the factor responsible for hyperpermeability. We also demonstrated that the vascular hyperpermeability produced by OHSS ascites was not abolished by specific neutralizing anti-VEGF
\end{abstract}

antibodies, and that not all of the VEGF found in the ascites fluid is biologically active. Moreover, our results strongly suggest that the vascular permeability produced by OHSS ascites may depend on activation of the kallikrein-kinin system. Possible evidence for this phenomenon was obtained by demonstrating that the hyperpermeability caused by the ascites could be blocked by Trasylol (known to inhibit bradykinin synthesis) and potentiated by captopril (a kininase II inhibitor). Taken together, the results suggest that, although VEGF is found in ascites fluid from patients with OHSS, it is unlikely that the cause of OHSS involves VEGF production by the ovaries. The kallikrein-kinin system may be more important in the hyperpermeability seen in OHSS.

Fournal of Molecular Endocrinology (1998) 20, 363-374

\section{INTRODUCTION}

Ovarian hyperstimulation syndrome (OHSS) is a severe complication arising from controlled ovarian stimulation treatment (Neulen et al. 1995). Clinical manifestations are massive extravascular fluid accumulation and hemoconcentration similar to that in syndromes associated with capillary leakage (Navot et al. 1992, Neulen et al. 1995). Ascites formation in OHSS is provoked systemically by a mediator produced by the ovaries (Espey et al. 1986, Navot et al. 1992, Yarali et al. 1993, McClure et al. 1994, Neulen et al. 1995). Although the pathophysiology of OHSS is still unknown, increased vascular permeability and ascites formation appear to be effects of vascular endothelial growth factor (VEGF) (Neulen et al. 1995). McClure et al. (1994) reported that the major capillary permeability agent in ascites fluid in OHSS is VEGF, since at least 70\% of the vascular permeability activity in OHSS is neutralized by an antiserum against intact VEGF.

VEGF, also known as vascular permeability factor, is a dimeric $34-49 \mathrm{kDa}$ glycoprotein which possesses potent vascular permeability-enhancing and endothelial cell-specific mitogenic activities. It may play an important role in the induction of vascular stroma, both as an endothelial growth factor and by increasing microvascular permeability to plasma proteins (Kondo et al. 1995). The active form of the VEGF species is a glycosylated $46 \mathrm{kDa}$ homodimer. The mitogenic activity of VEGF appears to be mediated by specific VEGF receptors, which are found on the cell surface of various endothelial cell types. 
Malignant ascites fluid is also largely the result of increased permeability of peritoneal lining vessels (Yeo et al. 1993). Tumors must induce a vascular stroma to grow beyond a minimal size. The intensity of the angiogenic response or expression of VEGF protein has been shown to correlate with prognosis in breast cancer patients (Brown et al. 1995). VEGF secretion by tumor cells is responsible for initiating and maintaining the ascites pattern of tumor growth (Nagy et al. 1995). Tumor ascites fluid accumulation may result from increased permeability of the blood vessels lining the peritoneal cavity, and this hyperpermeability may be mediated by VEGF secreted by ascites tumor cells (Olson et al. 1994).

Ovulation has been noted to bear a remarkable similarity to an inflammatory response (Espey et al. 1986). One of the principal components that is activated and mediates the events during an inflammatory response is the kallikrein-kinin system (Gao et al. 1992). Glandular or tissue kallikreins are a multigene family of serine proteases, of which six genes have been identified in the rat and are expressed in granulosa cells. Kallikrein-like enzyme activity has been detected during the periovulatory period in the gonadotropin-primed immature female rat ovary and suggested to play a role in the inflammatory-like response at ovulation (Espey et al. 1986, Clements et al. 1990). Its possible involvement in ovulation has previously been reported in the rat (Espey et al. 1986, Gao et al. 1992, Clements et al. 1990). Therefore the kallikrein-kinin system may also be a possible cause of the hyperpermeability produced in OHSS.

The purpose of the present study was to investigate and compare the mechanisms by which OHSS and ovarian carcinoma ascites fluids induce increases in microvascular permeability in rabbit skin. It is important to determine whether ascites fluids derived from OHSS and ovarian carcinoma contain VEGF. Two different assays were used to verify the presence of VEGF protein. One used an immunological method to characterize the secreted VEGF protein, and the second was a bioassay to detect VEGF-like mitogenic activity.

In addition, we examined whether ascites fluid from OHSS induces hyperpermeability through the kallikrein-kinin system. For this purpose we tested whether the hyperpermeability caused by the ascites can be blocked by Trasylol (known to inhibit bradykinin synthesis) and potentiated by captopril (a kininase II inhibitor). Our results strongly suggest that tumor ascites fluid accumulation is mediated by VEGF secreted by tumor cells and/or mononuclear cells, while the ascites fluid produced in OHSS is dependent, in whole or in part, on activation of the kallikrein-kinin system.

\section{MATERIALS AND METHODS}

\section{Characteristics of patients}

Patients undergoing in vitro fertilization treatment at Hamamatsu University Hospital and its related hospitals were recruited to the study, which had been approved by the institution ethical committee. All patients underwent ovarian stimulation using combined gonadotropin-releasing hormone agonist/ human menopausal gonadotropin and/or folliclestimulating hormone, using either the long or short (flare) protocol (Abdalla et al. 1989). Patients were monitored by regular transvaginal ultrasound scans until the criteria for human choriogonadotropin (hCG) administration were achieved (more than three follicles with mean diameter greater than $18 \mathrm{~mm}$ ). Patients received $5000 \mathrm{IU}$ hCG to induce final oocyte maturation, with a peak serum estradiol level of at least $500 \mathrm{pg} / \mathrm{ml}$ (1836 pmol/1). All accessible ovarian follicles were aspirated transvaginally $34 \mathrm{~h}$ after the $\mathrm{hCG}$ dose, and in vitro fertilization was performed in the usual manner (Abdalla et al. 1989). Patients were monitored closely for the onset of OHSS and were scanned 7 days after oocyte collection to assess ovarian size and to record the presence of free fluid in the pouch of Douglas.

Three patients with severe OHSS were initially seen, evaluated and treated by some of the authors. The patients were monitored by clinical examination and serum estrogen levels. Serum estrogen was determined using RIA. Data collected included patient age, parity, years of infertility, diagnosis, pre-hCG estrogen level, dose and duration of hMG and hCG treatments and resultant pregnancy. The classification of OHSS into mild, moderate or severe was made according to the criteria of Schenker \& Weinstein (1978).

In case 1 , the ovarian cysts grew slowly, and, within 2 days of hCG administration, the right ovary measured $5.5 \times 5.3 \mathrm{~cm}$ and the left measured $5.9 \times 4.7 \mathrm{~cm}$ with bilateral multicystic components. The patient complained of abdominal discomfort. Abdominal ultrasound examination revealed a large amount of free fluid in the peritoneal cavity. The ascites fluid was removed by peritoneal aspiration. At the same time, the patient received an infusion of albumin $(62.5-25.0 \mathrm{~g} /$ day $)$. The infusion was repeated on 5 consecutive days. The patient's symptoms gradually improved, and the ovaries decreased in size on removal of the free peritoneal 
TABLE 1. Characteristics of patients

Patients with OHSS

\begin{tabular}{|c|c|c|c|c|c|c|c|c|c|}
\hline & Age & Parity & $\begin{array}{l}\text { Years of } \\
\text { infertility }\end{array}$ & Diagnosis & $\begin{array}{l}\text { Serum E2 } \\
(\mathrm{pg} / \mathrm{ml})\end{array}$ & $\begin{array}{l}\text { hMG } \\
\text { dose per } \\
\text { day }(\mathrm{mg})\end{array}$ & $\begin{array}{l}\text { of } \mathbf{h M G} \\
\text { treatment } \\
\text { (days) }\end{array}$ & $\begin{array}{l}\text { Pregnancy } \\
\text { outcome }\end{array}$ & $\begin{array}{l}\text { VEGF level } \\
\text { in ascites } \\
(\mathrm{pg} / \mathrm{ml})\end{array}$ \\
\hline \multicolumn{10}{|l|}{ Case } \\
\hline 1 & 29 & 0 & 2 & $\mathrm{PCO}$ & $\mathrm{NT}$ & 150 & 8 & $\begin{array}{l}\text { Delivery of } \\
\text { healthy baby }\end{array}$ & 89 \\
\hline 2 & 34 & 0 & 7 & Tubal obstruction & 2540 & 150 & 10 & $\begin{array}{l}\text { Missed } \\
\text { abortion }\end{array}$ & 76 \\
\hline 3 & 31 & 0 & 4 & $\mathrm{PCO}$ & 3250 & 150 & 12 & $\begin{array}{l}\text { Delivery of } \\
\text { healthy baby }\end{array}$ & 45 \\
\hline
\end{tabular}

Patients with ovarian cancer

\begin{tabular}{|c|c|c|c|c|c|}
\hline & Age & Stage & Pathology & $\begin{array}{l}\text { Chemotherapy } \\
\text { regimen (course) }\end{array}$ & $\begin{array}{l}\text { in ascites } \\
(\mathrm{pg} / \mathrm{ml})\end{array}$ \\
\hline \multicolumn{6}{|l|}{ Case } \\
\hline 1 & 56 & IIIc & Serous & CDDP + CPM (7) & 2300 \\
\hline 2 & 68 & IIIc & Serous & CBDCA + CPM (13) & 3150 \\
\hline 3 & 49 & IV & Serous & CDDP + CPM (11) & 4120 \\
\hline 4 & 50 & IIIc & Clear cell & CDDP + Etoposide (11) & 2410 \\
\hline
\end{tabular}

VEGF level

in ascites

(1)

Severe OHSS consists of clinical evidence of ascites and/or pleural effusion, and respiratory, cardiac, or renal complications. The ovaries are significantly enlarged. In addition, hemoconcentration, electrolyte imbalance, hypotension, oliguria, azotemia and coagulation abnormalities can result. NT, not tested; PCO, polycystic ovary; E2, estradiol; Serous, serous cystadenocarcinoma of the ovary; Clear cell, clear cell carcinoma of the ovary; CDDP, cisplatin; CPM, cyclophosphamide; CBDCA, carboplatin. The intra-assay and interassay coefficients of variation were $6 \cdot 3$ and $8 \cdot 5 \%$ respectively.

fluid. A pelvic ultrasound examination performed 3 weeks after the albumin injection revealed both ovaries to be significantly reduced in size. The patient's symptoms resolved completely.

The characteristics of the other patients are summarized in Table 1.

\section{Materials}

The sources of materials used in this work were as follows: polyvinylidine difluoride (PVDF), protein assay kit (Bio-Rad); keyhole limpet hemocyanin, Evans blue, Trasylol, captopril, aprotinin, phenylmethylsulfonyl fluoride, iodoacetamide, $N$-ethylmaleimide (Sigma, St Louis, MO, USA); Freund's complete and incomplete adjuvant (Difco Laboratories, Detroit, MI, USA); Protein A-Sepharose, Protein G-Sepharose, PD-10 column, heparin-Sepharose and Sephadex 75 HR 10/30 (Pharmacia, Uppsala, Sweden); $\mathrm{Na}^{125} \mathrm{I}$ (Amersham, Tokyo, Japan). Recombinant human vascular endothelial growth factor $\left(\mathrm{rhVEGF}_{165}\right)$ is a $44 \mathrm{kDa}$ protein (composed of two $22 \mathrm{kDa}$ chains, each chain containing 165 amino acid sequences), which is produced from recombinant human DNA expressed in Sf9 baculovirus cells (Upstate Biotechnology, Lake Placid, NY, USA).

\section{Cells and culture}

U937, a human histiocytic lymphoma cell line, was a gift from Dr Naitoh (Department of 2nd Pathology, Hamamatsu University School of Medicine). U937 cells were grown in RPMI 1640 medium supplemented with $10 \%$ fetal calf serum. Cells were harvested by centrifugation. Growth conditions and maintenance were as previously described (Picone et al. 1989). We used the U937 cell line as a source of VEGF. Although we already had rhVEGF available from an apparently far more reliable source than conditioned medium from a cell line that undoubtedly contains a variety of other bioactive molecules, the U937 cell line was used for comparison with ascites fluid-derived VEGF.

Human umbilical vein endothelial cells (HUVECs) were grown in culture dishes coated with $1.5 \%$ bovine gelatin in the presence of growth medium (HuMedia-EGM-UV; Kurabo Co. Ltd, Tokyo, Japan) supplemented with $10 \%$ heatinactivated fetal calf serum. Cells were characterized as endothelial on the basis of typical cobblestone morphology and positive immunostaining for von Willebrand factor (Niedbala \& Stein 1991, 1992). 


\section{Collection and processing of human peritoneal effusions}

Seven peritoneal fluid samples (three from patients with severe OHSS and four from patients with epithelial ovarian carcinoma) that had been submitted for treatment purposes were collected at therapeutic paracentesis. Each ascites fluid was centrifuged at 3000 r.p.m. for $20 \mathrm{~min}$ at $4{ }^{\circ} \mathrm{C}$, and the clarified supernatants were stored frozen at $-80{ }^{\circ} \mathrm{C}$.

\section{Antibody preparation}

We synthesized a VEGF peptide corresponding to amino acid residues 1-26 of human VEGF: ${ }^{1}$ APMAEGGGQNHHEVVKFMDVYQRSYC ${ }^{26}$. New Zealand White rabbits $(2.0 \mathrm{~kg}$; SLC, Shizuoka, Japan) were immunized at multiple intradermal sites with an emulsion containing $1 \mathrm{mg}$ peptide-keyhole limpet hemocyanin conjugate in complete Freund's adjuvant; animals were subsequently boosted at 3-4 week intervals with an equivalent amount of the same conjugate in incomplete Freund's adjuvant. Collected serum was stored at $-20{ }^{\circ} \mathrm{C}$ before purification. Anti-VEGF polyclonal antibody was purified on a Protein G-Sepharose column using a commercial kit (HiTrap; Pharmacia). Rabbit polyclonal antibody raised against 26 -amino acid peptides corresponding to the $\mathrm{N}$-terminal sequence of human VEGF protein has a neutralizing effect on VEGF activity (see Figs 3, $5 a$ and 6).

\section{Immunoprecipitation}

Anti-human VEGF antibody-coupled Sepharose 4B beads $(20 \mu \mathrm{l})$ were added to $500 \mu \mathrm{l}$ of the ascites fluid. The volume was then adjusted to $1 \mathrm{ml}$ with reaction buffer, and the beads were allowed to react with the ascites fluid for $3 \mathrm{~h}$ at $4{ }^{\circ} \mathrm{C}$. The mixture was centrifuged for $5 \mathrm{~min}$ at 2500 r.p.m. The immunoprecipitate was washed five times with PBS, $\mathrm{pH} 7 \cdot 4$, and the pellet suspended in SDS sample buffer. The samples were boiled for $5 \mathrm{~min}$ and then centrifuged for $5 \mathrm{~min}$ to pellet insoluble material. Non-specific immunoprecipitate was measured by incubating ascites fluid with non-immune IgGcoupled Sepharose 4B beads. The precipitates were analyzed by SDS-PAGE (12\% gel) under nonreducing conditions. Gels were subsequently subjected to Western blot using anti-human VEGF antibody or anti-human $\alpha_{2}$-macroglobulin $\left(\alpha_{2} \mathrm{M}\right)$ antibodies.

In a separate experiment, the ascites fluid was passed three times through a $3 \mathrm{ml}$ anti-human VEGF antibody-coupled Sepharose 4B affinity column equilibrated with $\mathrm{PBS}, \mathrm{pH}$ 7.4. The purified material was eluted with $10 \mathrm{mM} \mathrm{HCl}$ and the peak fractions were stored, neutralized and dialyzed. The purified material was subsequently passed twice through a $0.5 \mathrm{ml}$ heparin-Sepharose column equilibrated with $\mathrm{PBS}, \mathrm{pH} 7 \cdot 4$. The unadsorbed fraction was enriched with VEGF- $\alpha_{2} \mathrm{M}$ complexes, and the adsorbed fraction contained mainly free VEGF. The VEGF-enriched fraction was eluted from the column with $1 \mathrm{ml}$ elution buffer $(20 \mathrm{mM}$ Tris- $\mathrm{HCl}$, pH $7 \cdot 0$, and $0.8 \mathrm{M} \mathrm{NaCl}$ ). Aliquots from both fractions were analyzed by SDS-PAGE $(12 \%$ gel), and the complexes and free VEGF were visualized using Western blot. The bands corresponding to the VEGF- $\alpha_{2} \mathrm{M}$ complexes and to the free VEGF were measured by densitometric scanning to determine the percentage of free VEGF in each fraction.

\section{Western blot}

Samples and purified VEGF protein were subjected to SDS-PAGE $(12 \%$ gel) under non-reducing conditions by the method of Laemmli (1970). Transfer of proteins to a PVDF membrane was performed by a semidry sandwich technique. Transfer was completed at $40 \mathrm{~mA} / \mathrm{gel}$ for $90 \mathrm{~min}$. The PVDF membrane was then blocked in buffer containing $2 \% \mathrm{BSA}$ in Tris-buffered saline, $\mathrm{pH} 8 \cdot 5$, for $60 \mathrm{~min}$ at $23{ }^{\circ} \mathrm{C}$ with gentle agitation. All washing of the membrane was carried out in Tris-buffered saline $/ 0 \cdot 05 \%$ Tween 20 . Primary and secondary antibody were diluted 1:100 and 1:500 respectively in blocking buffer. Each antibody incubation was at $23{ }^{\circ} \mathrm{C}$ for $1 \mathrm{~h}$. 4-Chloro-1naphthol substrate was added and the membrane was allowed to develop for $5 \mathrm{~min}$.

\section{Affinity precipitation}

Ascites fluid was harvested, cleared by centrifugation, and precipitated with $50 \mu \mathrm{l}$ heparinSepharose beads (Pharmacia) per $10 \mathrm{ml}$ of ascites fluid for $2 \mathrm{~h}$ at $23{ }^{\circ} \mathrm{C}$. The VEGF-heparin complexes were washed with precipitation buffer (150 mM NaCl, 1\% Nonidet P40, 0.5\% deoxycholate, $0 \cdot 1 \% \mathrm{SDS}, 50 \mathrm{mM}$ Tris, $\mathrm{pH} 8.0$ ), extracted with $50 \mu \mathrm{l}$ sample buffer, and analyzed by SDSPAGE (12\% gel), followed by Western blot.

\section{VEGF ELISA}

The concentration of VEGF in ascites fluid samples was determined by using a commercially available ELISA kit obtained from R\&D Systems (Quantikine VEGF immunoassay kit; Minneapolis, MN, USA). 


\section{Measurement of local edema formation in rabbit skin}

OHSS ascites fluid $(100 \mu \mathrm{l})$ or tumor ascites fluid $(100 \mu \mathrm{l})$ was incubated with Trasylol $(200 \mu \mathrm{g} / \mathrm{ml}$, $100 \mu \mathrm{l})$ or captopril $(100 \mu \mathrm{g} / \mathrm{ml}, 100 \mu \mathrm{l})$ for $30 \mathrm{~min}$ at $37^{\circ} \mathrm{C}$. Similar experiments were carried out with PBS $(100 \mu \mathrm{l})$ instead of Trasylol or captopril. In a parallel experiment, ascites fluid $(100 \mu \mathrm{l})$ was incubated with neutralizing polyclonal antibody against VEGF $(10 \mu \mathrm{g} / \mathrm{ml}, 100 \mu \mathrm{l})$ for $30 \mathrm{~min}$ at $37^{\circ} \mathrm{C}$. A $100 \mu \mathrm{l}$ volume of each mixture was injected intradermally into the shaved abdominal wall of a female New Zealand White rabbit.

Local edema formation was measured in the rabbits as the local accumulation of i.v. injected ${ }^{125}$ I-labeled human serum albumin $(2 \mu \mathrm{Ci} / \mathrm{kg})$ and Evans blue dye $(0.5 \mathrm{mg} / \mathrm{kg}, 2.5 \% \mathrm{w} / \mathrm{v})$ into skin sites as described previously (Kondo et al. 1995). After $30 \mathrm{~min}$, a $5 \mathrm{ml}$ blood sample was withdrawn into heparin. Blue spots that appeared on the injection sites were photographed. The injection sites were punched out and counted for radioactivity in a $\gamma$ counter. Edema formation at each site was expressed as plasma volume, calculated from the counts in $1 \mathrm{ml}$ plasma.

\section{VEGF protein purified from U937 culture medium and ascites fluids from patients with OHSS and ovarian carcinoma}

U937 cells were grown in suspension culture and the VEGF-containing serum-free conditioned medium was centrifuged and frozen at $-80{ }^{\circ} \mathrm{C}$ to provide a standardized preparation of human VEGF. Before centrifugation, protease inhibitors were added to the following final concentrations: iodoacetamide, $0.3 \mathrm{mg} / \mathrm{ml} ; N$-ethylmaleimide, $0.3 \mathrm{mg} / \mathrm{ml}$; phenylmethylsulfonyl fluoride, $0.3 \mathrm{mg} / \mathrm{ml}$; aprotinin, $200 \mathrm{KIU} / \mathrm{ml}$. The supernatants $(10 \mathrm{ml})$ were loaded on to an anti-human VEGF antibodycoupled Sepharose 4B column that had been equilibrated with Tris-buffered saline, $\mathrm{pH} 7 \cdot 3$. In a parallel experiment, ascites fluids obtained from patients with OHSS and ovarian carcinoma were also run through an anti-VEGF affinity column. After sample loading, the column was washed with equilibration buffer and eluted with $10 \mathrm{mM} \mathrm{HCl}$. Aliquots from $1 \mathrm{ml}$ column fractions were adjusted to $\mathrm{pH} 8.0$ and analyzed for VEGF by Western blotting using an antibody raised against a peptide representing the first 26 amino acids of the human VEGF N-terminal amino acid sequence. VEGF eluted from the column was pooled and dialyzed with $10 \mathrm{mM}$ sodium acetate $/ 0 \cdot 5 \mathrm{M} \mathrm{NaCl}, \mathrm{pH} 5 \cdot 2$. Samples were concentrated on an Amicon filter.
The amount of purified protein was determined using the Bio-Rad protein assay reagent (Bio-Rad, Hercules, CA, USA) with serially diluted BSA as standard (Conn et al. 1990, Houck et al. 1992, Disalvo et al. 1995). Biological activity of this VEGF protein was demonstrated by competition with binding of recombinant ${ }^{125} \mathrm{I}_{-} \mathrm{VEGF}_{165}$ to HUVECs and by its ability to stimulate proliferation of these cells (Nagy et al. 1995).

\section{Cell proliferation assay}

A suspension of HUVECs (passage 3) was prepared with endothelial cell basal medium supplemented with $10 \%$ fetal calf serum. Cells were seeded into a 24 -well plate $\left(5 \times 10^{3}\right.$ cells per well). After $24 \mathrm{~h}$, various assay specimens (either rhVEGF $_{165}$ or VEGF protein purified from ascites fluid or conditioned medium) were added to the culture medium. On day 4, medium and VEGF were replaced by fresh material. On day 7 , cells were washed, trypsinized, and counted. The experiment was performed twice with essentially identical results.

\section{DNA synthesis assay}

HUVECs were plated in complete tissue culture medium in 96-well culture plates at a cell density of $5 \times 10^{4}$ cells/well. After a $6 \mathrm{~h}$ incubation at $37^{\circ} \mathrm{C}$, ascites fluid $(20 \%$ of total volume) or serum-free medium alone and $1 \cdot 0 \mu \mathrm{Ci}$ of $\left[{ }^{3} \mathrm{H}\right]$ thymidine were added to each well. After an additional $24 \mathrm{~h}$ incubation, medium was gently aspirated and the cells were washed twice with serum-free medium. Cells were solubilized by addition of $1.5 \mathrm{M} \mathrm{NaOH}$ for $1 \mathrm{~h}$ at $23{ }^{\circ} \mathrm{C}$ and absorbed with cotton wicks. The cell-associated radioactivity was determined by liquid scintillation counting.

\section{Binding and competition assays}

rhVEGF $_{165}$ was iodinated by a modification of the chloramine $\mathrm{T}$ method (Waltz et al. 1993). VEGF $(60 \mu \mathrm{g})$ and $1 \mathrm{mCi} \mathrm{Na}^{125} \mathrm{I}$ were incubated in $6.5 \mu \mathrm{g} / \mathrm{ml}$ chloramine $\mathrm{T}$ in PBS for $45 \mathrm{~s}$ at $23{ }^{\circ} \mathrm{C}$, and the reaction was stopped with sodium metabisulfite. Labeled protein was separated from unbound ${ }^{125} \mathrm{I}$ by gel chromatography on a PD-10 column (Pharmacia) in PBS and stabilized with $0.2 \mathrm{mg} / \mathrm{ml}$ BSA. SDS-PAGE analysis followed by autoradiography revealed the expected molecular mass of $44 \mathrm{kDa}$ under non-reducing conditions.

Binding assays were performed at $4{ }^{\circ} \mathrm{C}$ by incubating HUVECs (passage $3 ; 1 \times 10^{5}$ cells $/ \mathrm{cm}^{2}$ ) for $3 \mathrm{~h}$ in 24 -well plates in a total volume of $300 \mu \mathrm{l}$ 

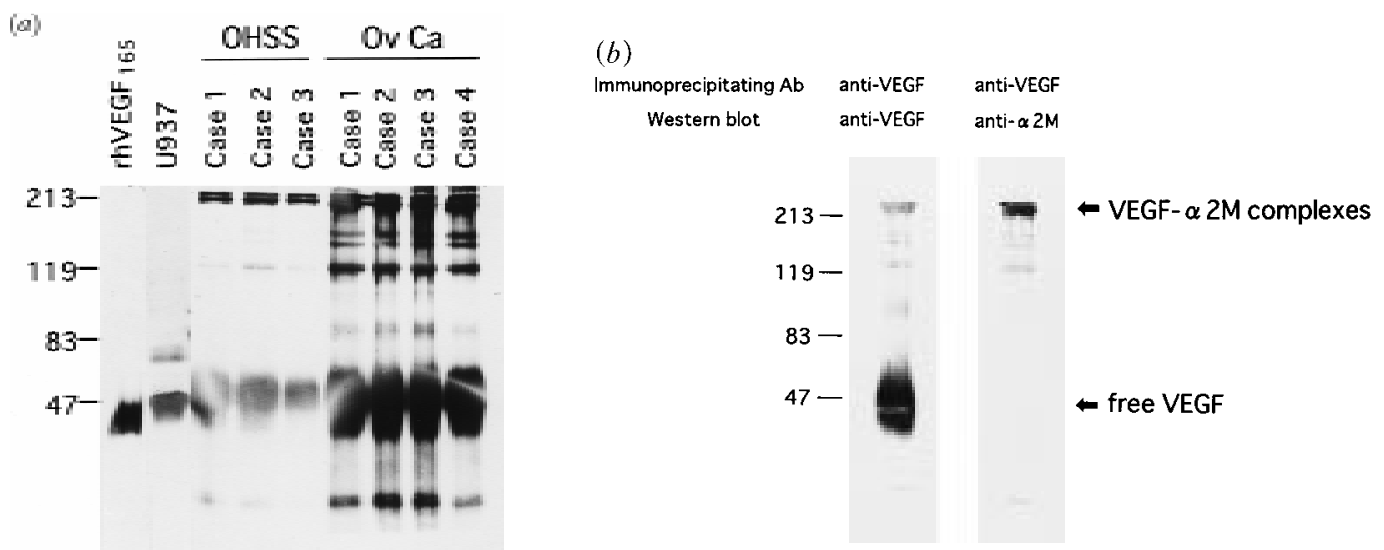

FIGURE 1. VEGF-like immunoreactive substances in ascites fluids. ( $a$ ) Aliquots of each sample (cases 1, 2, 3 and 4 ovarian carcinoma $(\mathrm{Ov} \mathrm{Ca})$ ascites fluids and cases 1, 2 and 3 OHSS ascites fluids) were precipitated using anti-VEGF-Sepharose beads and assayed by SDS-PAGE (12\% polyacrylamide gel) under non-reducing conditions. Western blot analysis was performed with a VEGF-specific polyclonal antibody. A rabbit was immunized by injecting the 26-amino acid synthetic peptide corresponding to the N-terminal sequence of human VEGF protein. Purified rhVEGF $_{165}$ and purified VEGF protein obtained from U937 cell-conditioned medium were mixed with non-reducing sample buffer and run on the same gel. Results are representative of three separate experiments. Biologically active VEGF proteins (44 and $49 \mathrm{kDa})$ in the Western blot were quantified by scanning densitometry (data not shown). The molecular mass of purified $\mathrm{rhVEGF}_{165}$ is $44 \mathrm{kDa}$. Marker proteins were 213,119, 83 and $47 \mathrm{kDa}$. (b) Co-precipitation of $\alpha_{2} \mathrm{M}$ with VEGF in ascites fluids. The ascites fluid supernatant (ovarian carcinoma case 1) was subjected to immunoprecipitation with antibodies to VEGF. The immunocomplexes were loaded on a $12 \%$ gel under non-reducing conditions. The gels were transferred to PVDF sheets and immunoblotted with antibodies to VEGF (lane 1) and $\alpha_{2} \mathrm{M}$ (lane 2) and developed with 4-chloro-1-naphthol.

Experiments using other ascites fluids gave essentially identical results.

of medium containing $1 \mathrm{mg} / \mathrm{ml}$ BSA, $20 \mathrm{mM}$ Hepes, pH 7·4, and ${ }^{125}$ I-VEGF (100 000 c.p.m.), with or without unlabeled competitor. The binding reaction was stopped by rinsing four times with cold medium, after which the cells were removed into $1 \mathrm{ml} 0 \cdot 6 \mathrm{M} \mathrm{NaOH}$ and radioactivity determined.

\section{RESULTS}

\section{VEGF-like immunological and biological activity in ascites fluid derived from OHSS and ovarian carcinoma}

The concentration of VEGF in the ascites fluid from each of the patients is shown in Table 1. There was significantly $(P<0.01)$ more VEGF in the ascites fluid of ovarian cancer patients $(2300,3150$, 4120 and $2410 \mathrm{pg} / \mathrm{ml}$ ) than in that of OHSS patients (89, 76 and $45 \mathrm{pg} / \mathrm{ml})$.

Aliquots of ascites fluid were immunoprecipitated using anti-human VEGF antibody-coupled Sepharose $4 \mathrm{~B}$ beads. The immunoprecipitation of VEGF was analyzed by SDS-PAGE under non-reducing conditions, followed by Western blot using anti- human VEGF antibody (Fig. 1a). The ascites fluid from ovarian carcinoma contains both free VEGF $(49 \mathrm{kDa})$ and VEGF-containing complexes of molecular mass higher than $200 \mathrm{kDa}$. Similar complexes were also observed in ascites fluid from OHSS patients. These complexes were also specifically immunoprecipitated with anti- $\alpha_{2} \mathrm{M}$ antibodies (see below). The low molecular mass bands and those between 83 and $200 \mathrm{kDa}$ are considered to be degradation products of the VEGF- $\alpha_{2} \mathrm{M}$ complexes, because they were immunoprecipitated with both VEGF and $\alpha_{2} \mathrm{M}$ antibodies (Fig. 1b). Western blot analysis of the immunoprecipitated products also indicated that free VEGF and VEGF- $\alpha_{2} \mathrm{M}$ complexes were present in both ascites fluids, but that a small amount of VEGF could be detected in OHSS ascites fluid (Fig. 1a). Densitometric scanning demonstrated that the free VEGF concentration in ovarian carcinoma ascites fluid is approximately 15 -fold higher than that in OHSS ascites fluid.

rhVEGF $_{165}$ and purified VEGF protein obtained from U937 cell-conditioned medium were used as positive controls. As shown in Fig. 1a, polyclonal 
antibody to VEGF recognizes only one protein band at $44 \mathrm{kDa}$ in the $\mathrm{rhVEGF}_{165}$ and at $49 \mathrm{kDa}$ and $70 \mathrm{kDa}$ in the conditioned medium from U937 cells. The small variation in size noted between samples is probably a consequence of differential glycosylation. In addition, this antibody obtained from rabbit immunized with a VEGF peptide selectively reacts with free VEGF protein $(49 \mathrm{kDa})$ and VEGF-containing complexes with molecular mass above $200 \mathrm{kDa}$ in the OHSS ascites fluids and in ascites fluid obtained from patients with ovarian carcinoma. It has been reported that a high molecular mass band corresponds to $\alpha_{2} \mathrm{M}-\mathrm{VEGF}$ complexes (Soker et al. 1993).

The ascites fluid supernatants were transferred to anti-VEGF antibody-coupled affinity Sepharose beads and allowed to tumble. The immunoprecipitated proteins were separated by SDS-PAGE. The immunopurified VEGF preparations from OHSS and ovarian carcinoma were assessed to be pure by silver staining (data not shown). Immunoblotting was performed with anti-VEGF antibody or anti- $\alpha_{2} \mathrm{M}$ antibody to confirm that $\alpha_{2} \mathrm{M}$ was part of the high molecular mass complexes. Commercial anti- $\alpha_{2} \mathrm{M}$ antibodies efficiently reacted with the VEGF-containing complexes from both ovarian carcinoma and OHSS ascites fluids, indicating that $\alpha_{2} \mathrm{M}$ is present in these high molecular mass complexes (Fig. 1b). In the Western blot using anti- $\alpha_{2} \mathrm{M}$ antibody, the polydisperse band of $49 \mathrm{kDa}$ corresponding to the expected size of VEGF dimers was not observed. Although Western blot analysis using anti-VEGF antibody demonstrates clearly that VEGF molecules present in various ascites fluids, e.g. OHSS and cancer, are immunologically identical, the concentrations of free VEGF were significantly higher in ovarian carcinoma ascites fluids than those in OHSS ascites fluids.

\section{Biological activity of VEGF protein}

It has been reported that specific binding of the VEGF- $\alpha_{2} \mathrm{M}$ complex-enriched fraction is much lower than that of the fraction enriched with free VEGF (Soker et al. 1993). We speculate that some of the immunoreactive VEGF in ascites fluid may be biologically inactive.

The ascites fluid samples used in the Western blot were also tested for VEGF-like mitogenic activity in an endothelial DNA synthesis assay (Fig. 2). Ascites fluids obtained from patients with OHSS and ovarian carcinoma as well as from serum-free conditioned medium from U937 were assayed for their ability to stimulate HUVEC proliferation.

Ascites fluid comprised only $20 \%$ of the incubation volume, therefore the magnitude of stimu-

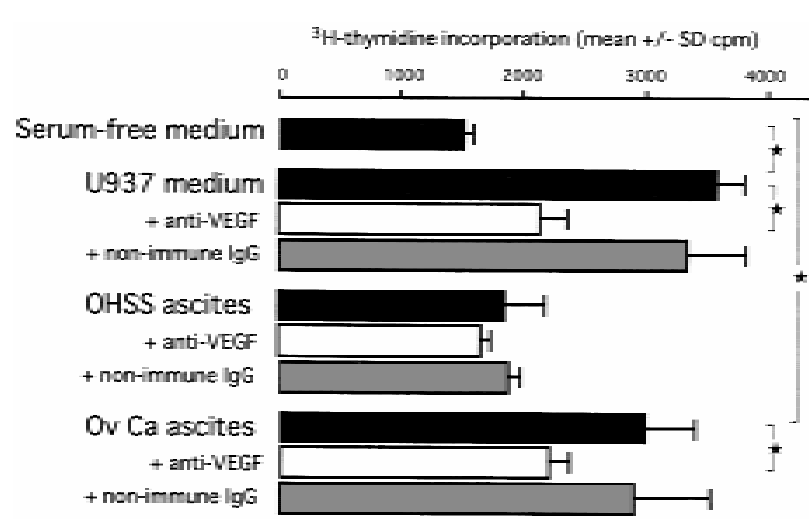

FIGURE 2. DNA synthesis assay in HUVEC culture. Ascites fluids obtained from patients with OHSS (case 1) and ovarian carcinoma ( $\mathrm{Ov} \mathrm{Ca}$, case 1), as well as serum-free conditioned medium from U937 cells, were assayed for the ability to stimulate HUVEC proliferation by $\left[{ }^{3} \mathrm{H}\right]$ thymidine incorporation. Serum-free medium added alone to endothelial cells was used as a control. $\mathrm{rhVEGF}_{165}(10 \mathrm{ng} / \mathrm{ml})$ and ascites fluids $(20 \%$ of incubation volumn) were added to the assay medium in the presence (open bars) or absence (solid bars) of anti-VEGF polyclonal antibody $(10 \mu \mathrm{g} / \mathrm{ml})$. Shaded bars: non-immune IgG. Bar, s.D. $(n=3)$. $* P<0 \cdot 05$.

lation may be limited by sample volume. U937 and ovarian carcinoma conditioned medium displayed approximately two- to three-fold stimulation over control serum-free medium. OHSS ascites fluid showed a slightly lower level of stimulation at $130 \%$ of controls. Biological mitogenic activity was found in ovarian carcinoma ascites, but not in OHSS ascites. Polyclonal antibody against VEGF neutralized the mitogenic activity induced by rhVEGF $_{165}$ and ovarian carcinoma ascites fluid, but did not inhibit that induced by OHSS ascites fluid (Fig. 2).

To discover whether purified ascites fluid-derived VEGF is biologically active, we tested and compared the mitogenic activity of the ascites fluids and purified rhVEGF $_{165}$ on HUVECs in vitro (Fig. 3). rhVEGF$_{165}$ and the purified proteins stimulated HUVEC growth with an $\mathrm{ED}_{50}$ of approximately $5.0 \mathrm{ng} / \mathrm{ml}\left(\mathrm{rhVEGF}_{165}\right.$ and U937) and $25.0 \mathrm{ng} / \mathrm{ml}$ (OHSS and ovarian carcinoma).

VEGF protein isolated from OHSS- and ovarian carcinoma-derived ascites fluids (which contain free VEGF and VEGF- $\alpha_{2} \mathrm{M}$ complexes) promoted proliferation of HUVECs, although the activity of the purified proteins was 5 -fold lower than that of rhVEGF $_{165}$. We confirmed that approximately one-fifth of immunoreactive VEGF can stimulate the growth of HUVECs. These results suggest that free VEGF, but not VEGF- $\alpha_{2} \mathrm{M}$ complexes, 


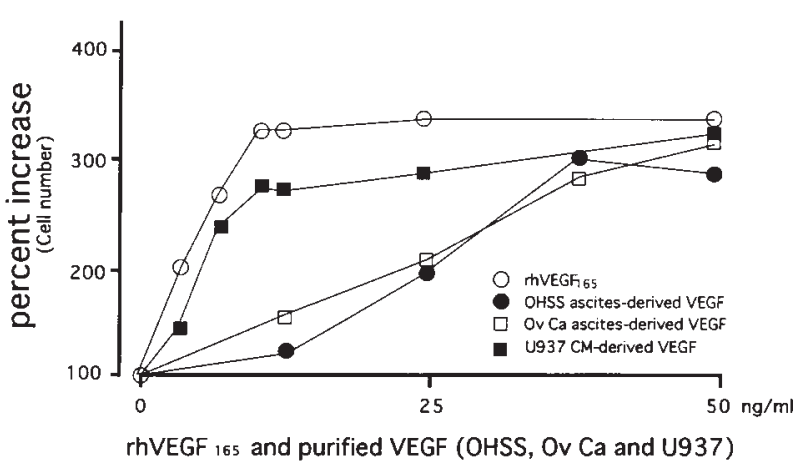

FIGURE 3. Stimulation of the growth of HUVECs in culture by ascites fluid-derived VEGF. HUVECs were seeded on 24-well plates and treated with either $\operatorname{rhVEGF}_{165}(\bigcirc)$ or purified VEGF protein from U937 conditioned medium ( $\square$ ), case 1 ascites fluid from OHSS ( ) or case 1 ascites fluid from ovarian carcinoma $(\square)$. After 7 days, cells were counted with a Coulter counter. rhVEGF $_{165}$ activity was determined as the ability to stimulate proliferation of HUVECs. The concentration of rhVEGF $_{165}$ required for half-maximum stimulation was approximately $2.5 \mathrm{ng} / \mathrm{ml}$. The experiment was carried out twice with essentially identical results. The amount of purified VEGF was estimated by ELISA and/or by Western blot and densitometric analysis. Results are the mean of two experiments, carried out on triplicate wells. Experiments using other ascites fluids gave essentially identical results. The S.D. of the mean was typically less than $12 \%$ of experimental values; no S.D. bars are given, for reasons of clarity.

present in OHSS and ovarian carcinoma is biologically active.

VEGF binds to specific receptors found on the cell surface of various endothelial cell types. To determine if the purified VEGF protein can bind to HUVEC-associated VEGF receptors, the purified protein was tested for competition with ${ }^{125} \mathrm{I}$-labeled rhVEGF $_{165}$ in a binding assay (Fig. 4a). ${ }^{125}$ I-VEGF binding to HUVECs was specifically inhibited by $\mathrm{rhVEGF}_{165}$ and the purified proteins with $\mathrm{ID}_{50}$ values of approximately $50 \mathrm{ng} / \mathrm{ml}\left(\mathrm{rhVEGF}_{165}\right.$ and U937) and $250 \mathrm{ng} / \mathrm{ml}$ (OHSS and ovarian carcinoma). It is unlikely that the differences in response curves observed in Figs 3 and $4 a$ reflect the purity of the two preparations compared with purified VEGF.

We next examined whether VEGF- $\alpha_{2} \mathrm{M}$ complexes bind to HUVECs. The complexes were separated from free VEGF on a heparin-Sepharose column. They did not bind to heparin-Sepharose since the heparin-binding domain of VEGF was masked as a result of its binding to $\alpha_{2} \mathrm{M}$. The unadsorbed fraction contained approximately $80 \%$ of the VEGF- $\alpha_{2} \mathrm{M}$ complex; the adsorbed material (a)

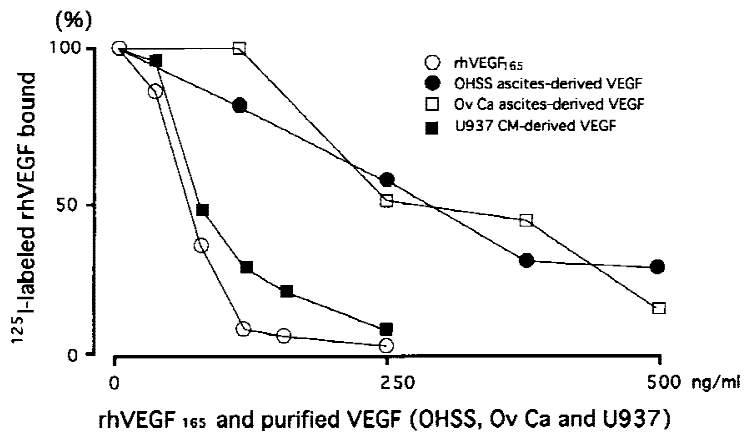

(b)

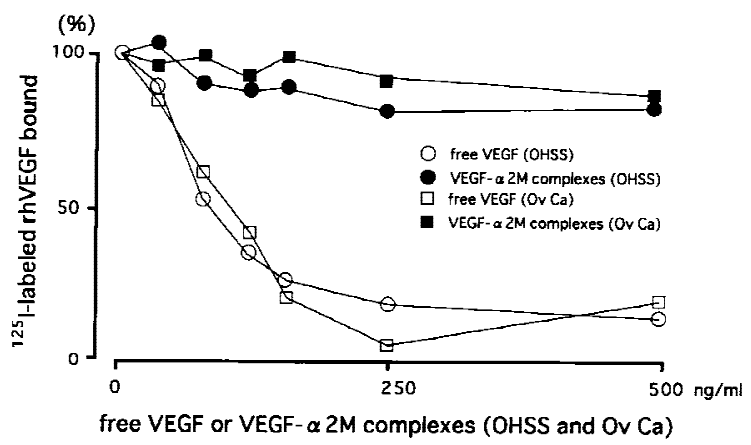

FIGURE 4. Competition of ${ }^{125}$ I-labeled rhVEGF $_{165}$ binding to HUVECs by purified VEGF protein.

(a) Confluent HUVECs (passage 2) were incubated with $1.5 \mathrm{ng} / \mathrm{ml}^{125} \mathrm{I}_{\text {-labeled }} \mathrm{rVEGF}_{165}$ and increasing amounts of either unlabeled $\operatorname{rhVEGF}_{165}(\bigcirc)$ or VEGF proteins purified from case 1 OHSS ascites fluid $(\bullet)$, case 1 ovarian carcinoma ascites fluid $(\square)$ or U937 cell conditioned medium ( $\mathbf{\square})$. The experiment was performed twice with essentially identical results. Results are the mean of two experiments, carried out on triplicate wells. Experiments using other ascites fluids gave essentially identical results. The s.D. of the mean was typically less than $10 \%$ of experimental values; no S.D. bars are given, for reasons of clarity.

(b) Competition of ${ }^{125}$ I-labeled rhVEGF ${ }_{165}$ binding to HUVECs by free VEGF and VEGF- $\alpha_{2}$ M complexes. Confluent HUVECs were incubated with $1.5 \mathrm{ng} / \mathrm{ml}$ ${ }^{125} \mathrm{I}_{\text {-labeled }}$ rhVEGF ${ }_{165}$ and increasing amounts of either free VEGF (Ov Ca, OHSS) or VEGF- $\alpha_{2} \mathrm{M}$ complexes (Ov Ca, OHSS). The experiment was performed twice with essentially identical results. Results are the mean of two experiments, carried out on triplicate wells. Experiments using other ascites fluids gave essentially identical results. The S.D. of the mean was typically less than $10 \%$ of experimental values; no S.D. bars are given, for reasons of clarity.

was released from the column using $0.8 \mathrm{M} \mathrm{NaCl}$ and contained $>90 \%$ free VEGF. We demonstrated that the binding of VEGF to $\alpha_{2} M$ inhibited its receptor-binding ability (Fig. 4b). Taking the results together, it is unlikely that the major capillary permeability-enhancing agent in OHSS 
ascites fluid is VEGF, although a biologically active free VEGF protein was observed in OHSS ascites.

\section{Vascular permeability caused by ascites fluids}

In further experiments, we investigated whether other mediators of increased microvascular permeability could also be involved in the response to intradermal ascites fluid injections. Ascites fluid from patients with OHSS was investigated for ability to stimulate vascular permeability by a Miles'-type assay and as the local accumulation of i.v. injected ${ }^{125}$ I-labeled human albumin in rabbit skin sites (Soker et al. 1993, Marangoni et al. 1993, Kondo et al. 1995). We demonstrated that cellfree peritoneal fluids from OHSS and ovarian carcinoma patients exhibited substantial vascular permeability-enhancing activity (Figs $5 a$ and $b$ ).

The kallikrein-kinin system may be involved in the ovulatory process and, in particular, the inflammatory-like changes including vascular hyperpermeability that occur around the time of ovulation. It is clear that the kallikrein-like activity is due to local synthesis of the enzyme, and six kallikrein gene family members are involved in the response (Clements et al. 1990). Trasylol is known to inhibit bradykinin synthesis and captopril is used as a kininase II inhibitor. The results of our experiments indicate that increased vascular permeability induced by OHSS ascites fluid is inhibited by Trasylol in rabbit skin. However, Trasylol failed to affect significantly the increased vascular permeability induced by tumor ascites fluid. The increased vascular permeability induced by OHSS ascites fluid was significantly potentiated by the kininase II inhibitor, captopril. At the dose used, captopril did not affect tumor ascites fluid-induced vascular permeability.

Further experiments were undertaken to determine whether VEGF is responsible for the microvascular permeability-enhancing activity in this animal model. In OHSS ascites fluids, the permeability-enhancing activity was detected in the pass-through fraction from heparin-Sepharose, while tumor ascites-derived permeability-enhancing activity was observed in the fractions bound to the heparin-Sepharose column (Fig. 6). Although Trasylol and captopril were also added to the VEGF group, they did not inhibit the vascular permeability-stimulating activity of VEGF (data not shown).

The purified rhVEGF $_{165}$ protein and tumor ascites fluids increased vascular permeability, and this was completely inhibited by anti-VEGF antibody. In contrast, the hyperpermeability induced by (a)

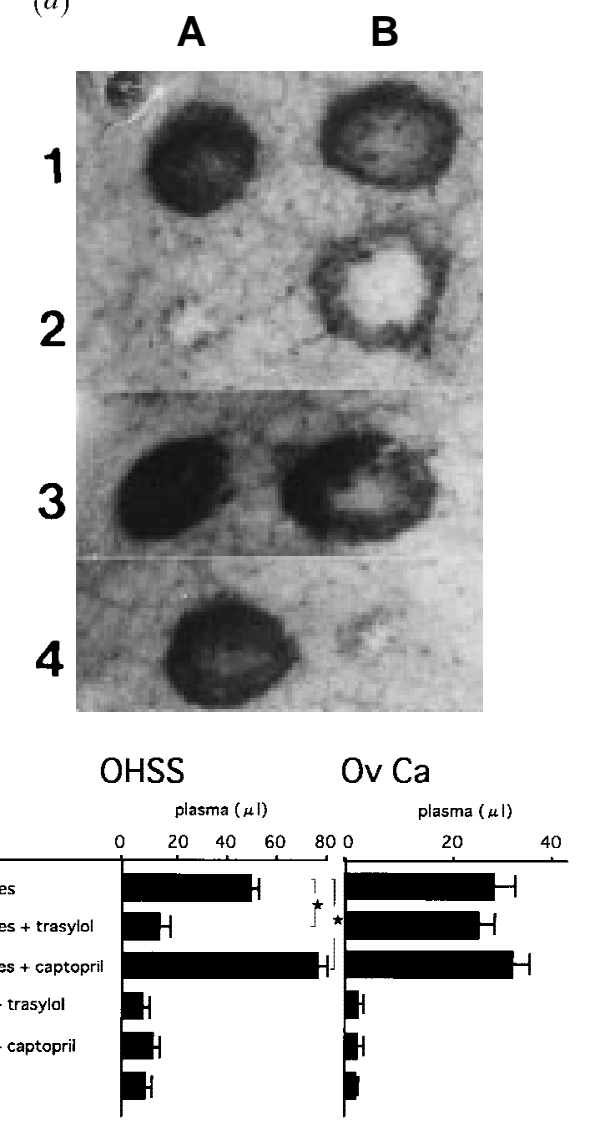

FIGURE 5. Vascular permeability assay of ascites fluids. Increased vascular permeability induced by ascites fluids is modulated by Trasylol or captopril in rabbit skin. Ascites fluids (case 1 OHSS (A) and case 1 ovarian carcinoma (B)) were injected alone (1) or co-injected with Trasylol (2), captopril (3) or anti-VEGF antibody (4). Evans blue dye and ${ }^{125}$ I-labeled human serum albumin $(2 \mu \mathrm{Ci} / \mathrm{kg})$ were injected i.v. into a rabbit. Ascites fluids treated with Trasylol or captopril were injected intradermally into the shaved abdomen of the rabbit. After $30 \mathrm{~min}$, blue spots caused by the extravasation of dye-stained proteins from vessels were photographed $(a)$. The injection sites were punched out and counted for radioactivity in a $\gamma$ counter $(b)$. The results are expressed as mean \pm S.D. from three rabbits. Experiments using other ascites fluid samples gave essentially identical results. ${ }^{*} P<0 \cdot 05$.

the OHSS ascites fluid was not inhibited by antiVEGF antibody. Dose-response curves were constructed to verify that there were no non-specific effects (data not shown). These findings suggest that ascites fluid accumulation in OHSS may result from increased permeability of the blood vessels lining the peritoneal cavity, which may be mediated by factors other than VEGF secreted by granulosa cells. Taken 


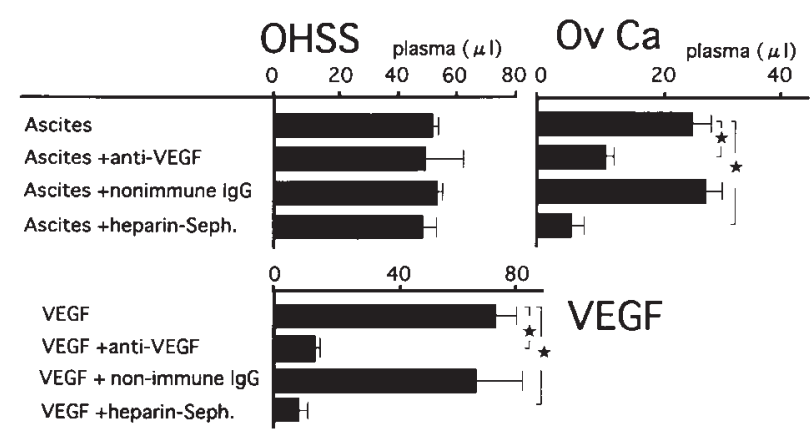

FIGURE 6. Modulation of ascites fluid-induced vascular permeability by anti-VEGF antibody and heparin-Sepharose. Increased vascular permeability induced by ascites fluids is modulated by anti-VEGF antibody (see Fig. $5 a$ ) or heparin-Sepharose in rabbit skin as described in the Fig. 5 legend. Ascites $(500 \mu \mathrm{l})$ or $\operatorname{rhVEGF}_{165}(500 \mu \mathrm{l}, 100 \mathrm{ng} / \mathrm{ml})$ was incubated with anti-VEGF antibody $(50 \mu \mathrm{l})$, non-immune $\mathrm{IgG}$ $(1 \mathrm{mg} / \mathrm{ml}, 50 \mu \mathrm{l})$ or heparin-Sepharose gel $(50 \mu \mathrm{l})$ for $60 \mathrm{~min}$ at $23^{\circ} \mathrm{C}$. After centrifugation, samples $(100 \mu \mathrm{l})$ were injected intradermally into the shaved abdominal wall of the rabbit. The injection sites were punched out and counted as described in the Fig. 5 legend. The results are expressed as mean \pm S.D. from three rabbits. Experiments using other ascites fluid samples gave essentially identical results. $* P<0 \cdot 05$.

together, the results indicate that the ascites fluidinduced increase in vascular permeability in OHSS occurs mainly as the result of kallikrein-kinin system activation.

\section{DISCUSSION}

We present a series of studies on ascites fluid from OHSS patients and patients with ovarian carcinoma. These fluids were analyzed in several bioassay systems and by Western blot and neutralizing antibody to identify the nature of the active principle responsible for the edema produced in the two clinical situations. VEGF in tumor ascites fluid has been implicated recently as an essential mediator of the microvascular hyperpermeability that induces or triggers ascites formation in patients with malignant disease (Gitay-Goren et al. 1992, Kondo et al. 1994, Rak et al. 1995). In the present study, however, the involvement of VEGF in ascites fluid-induced vascular permability in OHSS was not supported because of the following observations. The amount of biological active VEGF protein detected in OHSS ascites was significantly (8-fold) lower than that found in ovarian carcinoma ascites. The vascular permeability-enhancing activity in OHSS ascites fluid was not removed by
heparin-Sepharose chromatography. Anti-VEGF antibodies selectively inhibited tumor ascites fluidinduced local edema formation, but not the permeability effect of the OHSS ascites fluid. The failure of the anti-VEGF antibodies and heparinSepharose to prevent these reactions may eliminate the involvement of VEGF.

On the other hand, McClure et al. (1994) showed that about $70 \%$ of the vascular permeabilityenhancing activity in OHSS is neutralized by an antiserum raised against VEGF, which contradicts our results. In addition, Abramov et al. (1997) showed that VEGF levels can be much higher (average $500 \mathrm{pg} / \mathrm{ml}$ ) in OHSS ascites than that stated here. The reason why only the occasional patient treated for superovulation develops OHSS symptoms may be the wide variation in the level of VEGF or other capillary permeability-enhancing factors expressed in OHSS ascites by different individuals. Our observations were made when OHSS was already established. Since VEGF production may precede the development of clinical OHSS, it would be interesting to determine ascites and plasma VEGF levels before and after the development of clinical OHSS.

Two limitations of this study must be addressed. First, the anti-VEGF antibody used in this study may not recognize all forms of VEGF. Secondly, the low concentrations of VEGF in the OHSS ascites may be the result of the small sample sizes $(n=3)$. However, even though the number of patients is small, there is a clearcut difference in VEGF levels and the biological data.

OHSS ascites did not significantly stimulate DNA synthesis in the HUVEC culture (Fig. 2). Although ovarian carcinoma has more VEGF, it gives a much lower response than OHSS in our bioassay systems (Figs $5 a$ and 6). It is possible that other factors, which do not stimulate HUVEC DNA synthesis, are also present in OHSS ascites, including histamine, serotonin, ovarian prorenin, prolactin, platelet activating factor, leukotriene, bradykinin and the prostanoids, especially prostaglandin $\mathrm{E}_{2}$ (Navot et al. 1987, Yarali et al. 1993). However, we cannot rule out the possibility that the VEGF levels are still high enough to produce OHSS. We have demonstrated that VEGF in ascites fluid in OHSS is not involved in the hyperpermeability, but we cannot suggest what it might be doing.

Granulosa cells may produce VEGF that is regulated by $\mathrm{hCG}$ as well as proinflammatory stimuli (Neulen et al. 1995). Interestingly, the VEGF isolated from the OHSS ascites was separated into multiple forms according to molecular mass (free VEGF with molecular mass of $49 \mathrm{kDa}$ and VEGF $-\alpha_{2} \mathrm{M}$ complexes with molecular mass 
higher than $200 \mathrm{kDa}$ ). Since VEGF- $\alpha_{2} \mathrm{M}$ complexes are biologically inactive, $\alpha_{2} \mathrm{M}$ is thought to function in VEGF removal and inactivation. We need to establish a method of determining biologically active free VEGF in ascites fluid.

The involvement of the tissue kallikrein-kinin system in the microvascular hyperpermeability induced by OHSS ascites fluid is supported by several observations, although the present study cannot justify emphasis being placed on kinins alone. First, ovarian kinin-generating capacity was determined during induced ovulation in PMSG/ hCG-primed immature rats (Espey et al. 1986). It has been suggested that kinin-forming activity and kinins may have a role in the ovulatory process (Espey et al. 1986). Secondly, our results show that OHSS ascites fluid causes microvascular hyperpermeability by a mechanism that depends on the release of kinins, since the hyperpermeability is significantly inhibited by Trasylol and is potentiated by the kininase II inhibitor, captopril.

It is possible that OHSS ascites fluid causes microvascular hyperpermeability by activating and/or stimulating the secretion of tissue kallikrein localized in the ovaries, thereby causing the release of kinin. OHSS ascites fluid is known to contain kinins (H Kobayashi, Y Okada, T Asahina, J Gotoh \& T Terao, unpublished observations). Alternatively, OHSS ascites fluid could activate tissue prokallikreins. However, no kallikrein activator has been described in OHSS ascites fluid so far. A further possibility is that OHSS ascites fluid may itself contain active tissue kallikrein. The active fraction of the OHSS ascites fluid responsible for activation of the tissue kallikrein-kinin system has not been purified. A clear involvement of the kallikrein-kinin system might be seen if we were to measure tissue kallikrein in these ascites fluids. In the present study, evidence for the involvement of the kallikrein-kinin system is indirect and preliminary. Further biochemical studies are necessary to elucidate the mechanisms involved. Although our results suggest that tissue kallikrein or kallikrein activator may be important in vascular hyperpermeability in OHSS, the precise role of the kallikrein-kinin system remains to be established.

The possible role of the ovarian kallikrein-kinin and other endogenous vascular permeability systems in the systemic manifestation of OHSS leads to the consideration of kallikrein inhibitors and/or anti-kinin drugs for the prevention or modification of the course of OHSS. Trasylol has been shown to have a beneficial effect on the development of OHSS in an experimental animal model (H Kobayashi, Y Okada, T Asahina, J Gotoh \&
T Terao, unpublished observations). However, its safety in early human pregnancy remains to be established. Furthermore, it has many mechanisms of action; in addition to being a serine protease inhibitor, it also inhibits fibrinolysis. So, it is not clear that the effects seen are solely effects on the kallikrein-kinin system.

Identification of the factor(s) responsible for activation of the kallikrein-kinin system in OHSS ascites fluid might not only provide useful information on the role of the kallikrein-kinin activation system, but also increase the safety of patients undergoing ovulation induction therapy.

We analyzed fluid from a small sample of subjects with severe OHSS. Whether these results are applicable to the general population of women with OHSS is unclear. We are currently determining whether the kallikrein-kinin system, but not VEGF, is a major factor in the development of vascular permeability in fluid from a large sample of subjects with OHSS.

\section{REFERENCES}

Abdalla HI, Baber RJ, Leonard T, Kirkland A, Mitchell A, Power M, Owen E \& Studd JW 1989 Timed oocyte collection in an assisted conception programme using $\mathrm{GnRH}$ analogue. Human Reproduction 4 927-930.

Abramov Y, Barak V, Nisman B \& Schenker JG 1997 Vascular endothelial growth factor plasma levels correlate to the clinical picture in severe ovarian hyperstimulation syndrome. Fertility and Sterility 67 261-265.

Brown LF, Berse B, Jackman RW, Tognazzi K, Guidi AJ, Dvorak HF, Senger DR, Connolly JL \& Schnitt SJ 1995 Expression of vascular permeability factor (vascular endothelial growth factor) and its receptors in breast cancer. Human Pathology 26 86-91.

Clements JA, Mukhtar A, Holland AM, Ehrlich AR, \& Fuller PJ 1990 Kallikrein gene family expression in the rat ovary: localization to the granulosa cell. Endocrinology 136 1137-1144.

Conn G, Soderman DD, Schaeffer M-T, Wile M, Hatcher VB \& Thomas KA 1990 Purification of a glycoprotein vascular endothelial cell mitogen from a rat glioma-derived cell line. Proceedings of the National Academy of Sciences of the USA 87 1323-1327.

Disalvo J, Bayne ML, Conn G, Kwok PW, Trivedi PG, Soderman DD, Palisi TM, Sullivan KA \& Thomas KA 1995 Purification and characterization of a naturally occurring vascular endothelial growth factor/placenta growth factor heterodimer. Fournal of Biological Chemistry 270 7717-7723.

Espey LL, Miller DH \& Margolius HS 1986 Ovarian increase in kinin-generating capacity in PMSG/hCG-primed immature rat. American Fournal of Pathology 251 E362-E365.

Gao X, Greenbaum LM, Mahesh VB \& Brann DW 1992 Characterization of the kinin system in the ovary during ovulation in the rat. Biological Reproduction 47 945-951.

Gitay-Goren H, Soker S, Vlodavsky I \& Neufeld G 1992 The binding of vascular endothelial growth factor to its receptors is dependent on cell surface-associated heparin-like molecules. Fournal of Biological Chemistry 267 6093-6098. 
Houck KA, Leung DW, Rowland AM, Wine J \& Ferrara N 1992 Dual regulation of vascular endothelial growth factor bioavailability by genetic and proteolytic mechanisms. Fournal of Biological Chemistry 267 26031-26037.

Kondo S, Asano M, Matsuo K, Ohmori I \& Suzuki H 1994 Vascular endothelial growth factor/vascular permeability factor is detectable in the sera of tumor-bearing mice and cancer patients. Biochimica et Biophysica Acta 1221 211-214.

Kondo S, Matsumoto T, Yokoyama Y, Ohmori I \& Suzuki H 1995 The shortest isoform of human vascular endothelial growth factor/vascular permeability factor $\left(\mathrm{VEGF} / \mathrm{VPF}_{121}\right)$ produced by Saccharomyces cerevisiae promotes both angiogenesis and vascular permeability. Biochimica et Biophysica Acta 1243 195-202.

Laemmli UK 1970 Cleavage of structural proteins during the assembly of the head of bacteriophage T4. Nature 227 680-685.

Marangoni RA, Antunes E, Brain SD \& de Nucci G 1993 Activation by Phoneutria nigriventer (armed spider) venom of tissue kallikrein-kininogen-kinin system in rabbit skin in vivo. British of Fournal of Pharmacology 109 539-543.

McClure N, Healy DL, Rogers PA, Sullivan J, Beaton L, Hanning Jr RV, Connolly DT \& Robertson DM 1994 Vascular endothelial growth factor as capillary permeability agent in ovarian hyperstimulation syndrome. Lancet $344235-236$.

Nagy JA, Masse EM, Herzberg KT, Meyers MS, Yeo K-T, Yeo T-K, Sioussat TM \& Dvorak HF 1995 Pathogenesis of ascites tumor growth: vascular permeability factor, vascular hyperpermeability, and ascites fluid accumulation. Cancer Research 55 360-368.

Navot D, Margalioth EJ, Laufer N, Birkenfeld A, Relou A, Rosler A \& Schenker JG 1987 Direct correlation between plasma renin activity and severity of the ovarian hyperstimulation syndrome. Fertility and Sterility 48 57-61.

Navot D, Bergh PA \& Laufer N 1992 Ovarian hyperstimulation syndrome in novel reproductive technologies: prevention and treatment. Fertility and Sterility 58 249-261.

Neulen J, Yan Z, Paczek S, Weindel K, Keck C, Weich HA, Marme D \& Breckwoldt M 1995 Human chorionic gonadotropin-dependent expression of vascular endothelial growth factor/vascular permeability factor in human granulosa cells: importance in ovarian hyperstimulation syndrome. Fournal of Clinical Endocrinology Metabolism 80 1967-1971.
Niedbala MJ \& Stein M 1991 Tumor necrosis factor induction of urokinase-type plasminogen activator in human endothelial cells. Biomedicine Biochimica Acta 50 427-436.

Niedbala MJ \& Stein M 1992 Tumor necrosis factor induction of urokinase-type plasminogen activator mediated proteolysis of extracellular matrix and its antagonism by gamma interferon. Blood 79 678-687.

Olson TA, Mohanraj D, Carson LF \& Ramakrishnan S 1994 Vascular permeability factor gene expression in normal and neoplastic human ovaries. Cancer Research $\mathbf{5 4}$ 276-280.

Picone R, Kajtaniak EL, Nielsen LS, Behrendt N, Mastronicola MR, Cubellis MV, Stoppelli MP, Pedersen S, Dano K \& Blasi F 1989 Regulation of urokinase receptors in monocyte-like U937 cells by phorbol ester phorbol myristate acetate. Fournal of Cell Biology 108 693-702.

Rak J, Mitsuhashi Y, Bayko L, Filmus J, Shirasawa S, Sasazuki T \& Kerbel RS 1995 Mutant ras oncogenes upregulate VEGF/VPF expression: implications for induction and inhibition of tumor angiogenesis. Cancer Research $\mathbf{5 5} 4575-4580$.

Schenker JG \& Weinstein D 1978 Ovarian hyperstimulation syndrome: a current survey. Fertility and Sterility 30 255-268.

Soker S, Svahn CM \& Neufeld G 1993 Vascular endothelial growth factor is inactivated by binding to $\alpha_{2}$-macroglobulin and the binding is inhibited by heparin. Fournal of Biological Chemistry 268 7685-7691.

Waltz DA, Sailor LZ \& Chapman HA 1993 Cytokines induce urokinase-dependent adhesion of human myeloid cells. A regulatory role for plasminogen activator inhibitors. Fournal of Clinical Investigation 91 1541-1552.

Yarali H, Fleige-Zahradka BG, Yuen BH \& McComb PF 1993 The ascites in the ovarian hyperstimulation syndrome does not originate from the ovary. Fertility and Sterility $\mathbf{5 9}$ 657-661.

Yeo K-T, Wang HH, Nagy JA, Sioussat TM, Ledbetter SR, Hoogewerf AJ, Zhou Y, Masse EM, Senger DR, Dvorak HF \& Yeo T-K 1993 Vascular permeability factor (vascular endothelial growth factor) in guinea pig and human tumor and inflammatory effusions. Cancer Research $\mathbf{5 3}$ 2912-2918.

RECEIVED 19 August 1997 